\title{
Entre a glória e o esquecimento: a recepção da obra do escritor Coelho Neto
}

Between the glory and the oblivion: Coelho Neto's work reception

Entre gloria y olvido: la recepción de la obra del escritor Coelho Neto

Recebido: 15/05/2020 | Revisado: 16/05/2020 | Aceito: 19/05/2020 | Publicado: 30/05/2020

\section{Marcus Vinicius Sousa Correia}

ORCID: https://orcid.org/0000-0001-7735-6775

Universidade Estadual do Maranhão, Brasil

E-mail: marcusviniciuscxs@ @otmail.com

Emanoel Cesar Pires de Assis

ORCID: https://orcid.org/0000-0001-7377-8540

Universidade Estadual do Maranhão, Brasil

E-mail: emanoel.uema@gmail.com

\section{Resumo}

O presente artigo realiza um breve estudo sobre o lugar ocupado por Coelho Neto dentro da historiografia da literatura brasileira, considerando a sucessão de recepções positivas e negativas que o literato teve ao longo de sua carreira como escritor e, através de estudos crítico-teóricos, objetiva esclarecer como fatores literários e extraliterários influenciaram o público-leitor e as interpretações por ele feitas a respeito das obras do escritor. Foi possível concluir que, em diferentes esferas, as interpretações feitas sobre as obras de Coelho Neto foram condicionadas por ideais a serem atingidos e pelo interesse de descreditar o escritor maranhense.

Palavras-chave: Coelho Neto; Recepções; Público-leitor; Influências; Leitura.

\begin{abstract}
This article makes a brief study of the place occupied by Coelho Neto within the historiography of Brazilian literature, considering the succession of positive and negative receptions that the he had throughout his career as a writer and, through critical-theoretical studies, aims at clarifying how literary and extraliterary factors influenced the reading
\end{abstract}


(CC BY 4.0) | ISSN 2525-3409 | DOI: http://dx.doi.org/10.33448/rsd-v9i7.4552

audience and the interpretations made regarding the writer's works. It was possible to conclude that, in different spheres, the interpretations made on Coelho Neto's works were conditioned by ideals to be reached and by the interest of discrediting the writer from Maranhão.

Keywords: Coelho Neto; Receptions; Reading audience; Influences; Reading.

\section{Resumen}

Este artículo hace un breve estudio sobre el lugar ocupado por Coelho Neto dentro de la historiografía de la literatura brasileña, considerando la sucesión de recepciones positivas y negativas que el esccritor tuvo a lo largo de su carrera como escritor y, a través de estudios crítico-teóricos, pretendemos aclarar cómo los factores literarios y extraliterários indujeron los lectores y las interpretaciones hechas por ellos acerca de las obras del escritor. Fue posible concluir que, em diferentes ámbitos, las interpretaciones hechas acerca de las obras de Coelho Neto estaban condicionadas por los ideales a alcanzar y por el interés de desacreditar el escritor de Maranhão.

Palabras clave: Coelho Neto; Recepciones; Lectores, Inducción; Lectura.

\section{Introdução}

Henrique Maximiano Coelho Neto, escritor nascido em Caxias - MA, foi um literato prestigiado e uma importante figura para o cenário literário brasileiro de sua época, sendo, inicialmente, bem recebido pela crítica literária e ocupando importantes cargos na sociedade ${ }^{1}$. Coelho Neto, além de escritor, foi professor, político, crítico de arte, cronista e teatrólogo, e também dono de uma extensa produção literária, composta por mais de 130 volumes e crônicas publicadas em jornais da época, no Brasil e no exterior. Em 1928, foi eleito Príncipe dos Prosadores Brasileiros, deixando em segundo lugar Monteiro Lobato, através de um concurso realizado pela revista $O$ Malho, que entrevistou críticos e literatos influentes daquele período.

Sendo assim, é impossível negar o grande valor de Coelho Neto para a literatura nacional, e acrescenta-se a isso os elogios de escritores contemporâneos a ele, como Machado

\footnotetext{
${ }^{1}$ Panoramas mais detalhados sobre a vida e a obra do autor, bem como algumas pesquisas mais recentes feitas sobre a sua obra podem ser encontradas em Assis e Sousa (2017) e Sousa, Correia e Assis (2018).
} 
de Assis (1895) que, em uma de suas crônicas, afirma que o literato maranhense, além de possuir o dom da invenção, era um "observador de pulso".

Adolfo Caminha (1895), em suas Cartas Literárias, faz menções a Coelho Neto, colocando-o, junto a Aluísio Azevedo, como um escritor dotado de um método eficaz para a composição de seu objeto artístico. Referindo-se à sua época, o crítico afirma: "Aluísio e Coelho Neto são, pois, ao meu ver, os dois mais operosos escritores brasileiros da atualidade" $(\text { Ibid, } 1895, \text { p. 10) })^{2}$. No mesmo livro, Caminha dedica um de seus ensaios somente a Coelho Neto, comentando sobre A capital federal (1893), no qual fala sobre as qualidades por ele percebidas na escrita coelhonetiana, atestando que "em Coelho Neto, observa-se a preocupação do estilo simples, da forma comunicativa, que caracteriza os grandes artistas" (Caminha, 1895, p. 61).

Entretanto, diferente de alguns contemporâneos seus, como o próprio Machado de Assis e Aluísio Azevedo, Coelho Neto foi parcialmente esquecido entre os leitores e estudiosos de literatura. Nos processos de recepção e crítica literárias, as obras do literato maranhense foram alvo de comentários depreciativos, principalmente por escritores e outros artistas da Semana de Arte Moderna de 1922. Mas, apesar de a Semana de 22 ser um acontecimento muito influente na rejeição e no esquecimento da prosa coelhonetiana, é necessário que outros fatores, literários e extraliterários, sejam considerados para uma compreensão mais pertinente sobre o processo de esquecimento pelo qual passou o Príncipe dos Prosadores. Partindo disso, o presente estudo tem o objetivo de esclarecer de que modo fatores literários e extraliterários influenciaram as interpretações feitas pelo público-leitor sobre as obras de Coelho Neto.

Nesse sentido, é interessante a perspectiva apresentada por Carlos Eduardo de Oliveira Bezerra (2009), que identifica fatores econômicos e estruturais, refletidos na vontade dos editores de obterem lucro e nas dificuldades de impressão dos livros, por conta da ausência de bons equipamentos para a impressão, que interferiam diretamente na presença, ou na ausência, de determinados escritores no mercado literário. Outros aspectos apontados por Bezerra (2009), referentes ao conteúdo das obras, eram o tom memorialístico e certas críticas presentes nos livros de alguns escritores, levando-os ao esquecimento entre os literatos de destaque. Nas palavras do autor:

\footnotetext{
${ }^{2}$ Textos escritos em épocas mais antigas, ao serem citados, estão de acordo com a grafia utilizada na época em que este trabalho foi produzido.
} 
Esse caráter memorialístico do texto literário e do texto crítico parece ter sido a causa, por exemplo, para que autores, como o já citado Coelho Neto, fossem esquecidos e quase não figurem nas prateleiras das livrarias, ou sejam lembrados por leitores atuais como a mesma facilidade que o foram por leitores no passado (Bezerra, 2009, p. 133).

A partir do que é afirmado por Bezerra (2009), é possível perceber que a ausência das produções de Coelho Neto nas livrarias e no grupo de obras canônicas não é, grosso modo, justificada por uma falta de características agradáveis ou interessantes nos livros escritos pelo Príncipe dos Prosadores. Os interesses dos demais envolvidos no mercado literário da época, como os editores e os vendedores, influenciavam diretamente no que era consumido pelos leitores, construindo certas condutas para eleger as obras ditas de qualidade.

Além disso, é pertinente lembrar que antes do boom modernista de 22, já existiam comentários críticos que identificavam determinados problemas, tanto na escrita quanto no conteúdo, das narrativas de Coelho Neto, que datam da mesma época na qual foram publicadas as primeiras obras do literato caxiense. Na recepção crítica inicial da prosa coelhonetiana, apesar de positiva, já é possível perceber observações que elencavam aspectos das produções do escritor maranhense que, para a crítica, configuravam-se como problemas ou defeitos na construção das obras. Tal fato é mais um indício de que a Semana de 22 não é o fator de maior influência na negação da literatura produzida por Coelho Neto, diferente do que, em certa medida, é senso comum na historiografia literária. Após essa primeira recepção, os problemas identificados passaram a ser o principal foco da maioria dos críticos que falavam sobre as obras de Coelho Neto.

O próprio Adolfo Caminha (1895), apesar dos elogios, já falava da existência de inadequações nas obras do literato maranhense. Caminha (1895) afirmava, já de início, que Coelho Neto não tinha ainda um ideal artístico claro, por conta do ecletismo nas produções coelhonetianas que variavam bastante, vendo problemas nisso. Em um de seus comentários, o crítico e também escritor é um tanto quanto sutil ao mencionar um problema por ele visto nos livros coelhonetianos, ao afirmar que "Coelho Neto, cujo estilo quando não descamba para o orientalismo artificioso e fatigante, consegue sempre agradar" (Caminha, 1895, p. 09).

Além disso, outro fator negativo para Caminha centra-se diretamente na escrita, especificamente na preferência de Coelho Neto por termos arcaicos ou de uso pouco frequente no Brasil. Ao ocupar-se da crítica sobre Praga (1894), pequena obra de Coelho Neto, Caminha elenca as qualidades do livro, qualificando-o como peça-chave para entender o "temperamento literário" de Coelho Neto, mas, ao fim, assevera: 
Uma coisa, porém, me desgosta em Praga e em quase todos os escritos de Coelho Neto: o amaneirado inútil da adjetivação, o emprego desnecessário e mesmo antiestético de vocábulos raros, cuja presença nem sempre dá mais força e beleza à expressão, tornando-a, pelo contrário, vaga e prosaica. [...] Em tudo mais ele é um verdadeiro prosador, e dos que honram a literatura nacional (Caminha, 1895, p. 103104).

Adolfo Caminha também menciona essa falta de permanência do escritor caxiense em uma corrente estética, afirmando ser essa característica um indício de que Coelho Neto ainda não possuía um ideal artístico claro, qualificando-a como um possível problema. Soma-se a isso a frequência com a qual Coelho Neto escrevia e publicava livros, justificada pelo fato de Coelho Neto obter sua renda através da venda de seus livros, o que Caminha também vê como um problema.

Outro crítico que fez comentários muito influentes na fortuna crítica de Coelho Neto foi José Veríssimo e cabe lembrar a afirmação de Marcos Aparecido Lopes (1997) ao identificar que "as restrições feitas por Veríssimo à obra de Coelho Neto iniciam o processo de deslegitimação literária deste escritor [...]" (Lopes, 1997, p. 16). Nesse sentido, é pertinente que sejam analisadas as postulações feitas por José Veríssimo sobre o material literário produzido por Coelho Neto, considerando que o crítico tinha um apreço ambíguo pela carreira literária do prosador maranhense. Os comentários de Veríssimo, como será possível perceber, passeiam entre o otimismo e o pessimismo em relação às obras de Coelho Neto, verificando qualidades e defeitos que, para o crítico, identificavam as características e o compromisso, ou a falta dele, nos livros coelhonetianos.

Veríssimo (1901) identifica Coelho Neto, inicialmente, como um escritor com o qual a literatura nacional poderia contar, sendo dotado de significativo talento para as artes literárias. Com isso, é nítido o otimismo do crítico em relação à qualidade do que Coelho Neto produzia, porém, Veríssimo reconhece, e lamenta, certa pressa no processo criativo de Coelho Neto, fazendo referência ao número de obras produzidas pelo Príncipe dos Prosadores. Para o crítico, a frequência de escrita e de publicação de Coelho Neto acontecia "com uma fertilidade que não pode deixar de prejudicar-lhe a perfeição e a qualidade" (Veríssimo, 1901, p. 244). Ao elencar mais defeitos do que qualidades, Veríssimo realiza, como já mencionado anteriormente, o início de uma sistemática desvalorização das obras de Coelho Neto.

Ainda sobre as avaliações de José Veríssimo, é importante ressaltar os aspectos extraliterários que, em certa medida, influenciaram os julgamentos feitos pelo crítico não apenas sobre Coelho Neto, mas também a respeito de toda a arte literária produzida no Brasil. 
José Veríssimo baseava-se, em suma, na ideia da necessidade de ser construída uma cultura nacional de relevo, sem a influência exacerbada de outras nações, como Portugal, nas produções literárias brasileiras. Na visão do crítico, tal exagero de inspiração na cultura exterior resultava em uma imitação desprovida de significativa qualidade literária.

A influência desta linha de pensamento no modo de julgamento usado por Veríssimo se manifesta, também, quando o crítico cita o uso que o literato maranhense faz de referências da Grécia e do Oriente, vendo isto como um ornamento superficial que não traz uma contribuição efetiva para os livros de Coelho Neto, participando das obras apenas como "um motivo decorativo novo, ou com aparência, ao menos, de novidade, própria para enganar os ingênuos" (Ibid, 1904, p. 07).

Ao escrever Estudos de literatura brasileira - sexta série (1907), José Veríssimo menciona, novamente, o Príncipe dos Prosadores, comentando, sobre os novos livros e a respeito da escrita de Coelho Neto, que não há "nenhuma mudança de fundo ou de forma" (Verissimo, 1907, p. 250). Diante disso, o crítico faz, indiretamente, uma cobrança ao literato maranhense a respeito do compromisso nacional que um escritor brasileiro, de acordo com ele, deveria ter. Veríssimo o faz dizendo:

Entenda-se que eu não pretendo que os escritores brasileiros evitem os termos portugueses, ao contrário, eu sou pelo respeito à vernaculidade (não ao purismo, que é insensato) da nossa língua. Parece-me, porém, que o escritor brasileiro deve, independentemente de qualquer sentimento de nacionalismo ou nativismo, mas cedendo somente às necessidades de uma boa escrita literária, das quais uma das primeiras é que entendem os nossos leitores naturais, preferir as formas nacionais às estranhas. É exatamente o contrário que faz o Sr. Coelho Neto (Ibid, 1907, p. 252).

É possível perceber que as críticas negativas feitas por Adolfo Caminha e por José Veríssimo apontam para as mesmas características de Coelho Neto e suas obras: a adjetivação exagerada, a frequência de escrita e de publicação dos livros, o desagrado referente ao ecletismo estético das obras coelhonetianas, o uso de palavras desusadas no Brasil e, diga-se de passagem, a preferência pelos contos escritos por Coelho Neto em detrimento das obras mais longas. Esses foram fatores utilizados com frequência pela crítica literária para sustentar argumentos que descreditavam as obras do prosador maranhense e, além desses, é necessário considerar um fator primordial nas alegações negativas sobre os livros de Coelho Neto: a forma de escrita. 


\section{Metodologia}

Para a realização deste estudo foi usada como metodologia de pesquisa a revisão bibliográfica de alguns livros critico-teóricos e de artigos, dissertações e teses que, grosso modo, mencionam Coelho Neto e as obras literárias por ele escritas e emitem juízos críticos sobre isso e também sobre os contextos nos quais foram escritos, publicados e lidos os livros do literato maranhense. Com a visão do panorama que tais considerações revelam foram utilizados, por oferecerem suporte metodológico sobre a pesquisa aqui realizado, as contribuições dos estudos teóricos de Jauss (1994) e Stierle (1979), que versam sobre as possíveis influências que fatores literários e extraliterários exercem sobre as interpretações de obras e de escritores. Os materiais utilizados datam das primeiras críticas mais significativas dirigidas ao escritor Coelho Neto e às suas obras até estudos contemporâneos que possuem o escritor e suas obras como objeto de análise e pesquisa.

É de suma importância a apresentação do que foi dito por alguns dos principais autores componentes da fortuna crítica de Coelho Neto: Adolfo Caminha (1895); José Veríssimo (1901, 1904, 1907); Lima Barreto (1918); Humberto de Campos (1962); Brito Broca (1958); além do literato Machado de Assis (1895) que fez comentários sobre Coelho Neto em algumas de suas crônicas. Além disso, mas ainda sobre críticas a respeito de Coelho Neto, é relevante o que é dito nos trabalhos acadêmicos Lopes (1997); Bezerra (2009) Gonçalves (2016); Sousa \& Assis (2017); Sousa, Correia \& Assis (2018) e Assis \& Lopes (2019). Tais estudos são utilizados pelo fato de, a partir de diferentes prismas e épocas, apresentarem os principais aspectos das obras de Coelho Neto e juízos críticos a respeito disso.

\section{Estilo de Escrita: A Subversão de Coelho Neto}

Dentre os aspectos constituintes das obras literárias de Coelho Neto, um dos que sempre foi visto com maus olhos é a escolha do autor por um uso rebuscado da língua portuguesa, valorizando termos arcaicos ou de uso mais recorrente em Portugal, além de dar destaque às descrições das paisagens em suas obras. A crítica literária, ao reconhecer tal característica, e por julgá-la como desnecessária e até mesmo negativa, passou a utilizá-la como um aspecto crucial para verificar a qualidade, ou a ausência dela, no material literário produzido por Coelho Neto. Nesse sentido, é pertinente que seja brevemente revisto o modo como a forma de escrita coelhonetiana era analisada. 
O estilo de escrita e as descrições de Coelho Neto eram acompanhados por afirmações que, em suma, deflagravam o aspecto prejudicial do conjunto de fatores formadores do estilo de escrita do Príncipe dos Prosadores. O já citado José Veríssimo (1907) critica, além do que já foi mencionado, a respeito dessa preferência estilística, especificamente sobre o uso de vocábulos mais usados em Portugal. O crítico assevera que a linguagem de Coelho Neto "é portuguesa de lei, mas com rebuscamentos classicistas, superabunda mais do que conviria a um escritor brasileiro de vocábulos unicamente portugueses, já sem curso no Brasil” (Veríssimo, 1907, p. 251). Esse rebuscamento foi o principal alvo de modernistas que pregavam a inovação no fazer literário, defendendo a representação e a valorização da cultura dita genuinamente brasileira.

Lima Barreto (1918), que pode ser considerado o símbolo da visão que os modernistas possuíam sobre Coelho Neto, em muitas ocasiões teceu comentários negativos a respeito do estilo de escrita empregado pelo literato maranhense, tendo em vista o vocabulário e as referências à Grécia. Para Lima Barreto, esses elementos nada acrescentavam ao povo brasileiro e, além disso, impediam a realização de análises pertinentes sobre a complexa situação social na qual se encontrava a maioria das pessoas no Brasil. Coelho Neto também foi deputado eleito pelo estado do Maranhão e Lima Barreto, relacionando a vida política ao estilo de escrita coelhonetiano, mencionou novamente o que ele entendia como falta de compromisso com questões sociais por parte de Coelho Neto, colocando em xeque até mesmo a atuação política do escritor caxiense:

O deputado ficou sendo o romancista que só se importou com o estilo, com o vocabulário, com a paisagem, mas que não fez do seu instrumento artístico um veículo de difusão das grandes ideias do tempo; em quem não repercutiram as ânsias de infinita justiça dos seus dias; em quem não encontrou eco nem revolta o clamor das vítimas da nossa brutalidade burguesa, feita de avidez de ganho, com a mais sinistra amoralidade para também edificar, por sua vez, uma utopia ou ajudar a solapar a construção social que já encontrou balançando (Barreto, 1918, citado por Rosso, 2010, p. 37).

É possível perceber que Lima Barreto não criticava apenas o estilo de escrita do prosador maranhense, mas, através disso, os comentários negativos, e por vezes claramente ofensivos, tinham como alvo o próprio Coelho Neto, e não apenas o material literário por ele produzido ou a sua forma de escrever. Por esse viés, é possível perceber que o estilo de escrita do romancista maranhense foi além da própria literatura, sendo utilizado até mesmo para que a pessoa de Coelho Neto fosse alvo de críticas depreciativas. Lima Barreto afirma ainda que a 
literatura do prosador maranhense "ficou sendo puramente contemplativa, estilizante, sem cogitações outras que não as da arte poética, consagrada no círculo dos grandes burgueses embotados pelo dinheiro" (Barreto, 1918, citado por Rosso, 2010, p. 37-38).

Dado o exposto, cabe aqui citar outro ensaio crítico de Lima Barreto, talvez o que melhor representa a visão do crítico e escritor modernista sobre Coelho Neto, intitulado Histrião ou literato? no qual Lima Barreto qualifica o prosador maranhense como "o sujeito mais nefasto que tem aparecido em nosso meio intelectual" (Barreto, 1919, citado por Rosso, 2010, p. 73). Em suma, para Lima Barreto, o Príncipe dos Prosadores representava a expressão literária com muita forma e pouco, ou nenhum, conteúdo, afirmando até mesmo que Coelho Neto não seria capaz de elaborar um pensamento que estivesse de acordo com a realidade da população brasileira, ou sequer tinha conhecimento sobre ela, entendendo que o escritor maranhense a ignorava, por não produzir uma literatura que tivesse o compromisso social que Lima Barreto entendia como a função primordial da literatura e, além disso, asseverou que o literato maranhense "fossilizou-se na bodega que ele chama de estilo" (Barreto, 1919, citado por Rosso, 2010, p. 73).

Cabe lembrar que os modernistas de 22, apesar da dita inovação no fazer artístico, foram fortemente influenciados pelos juízos críticos do passado e, diferente do que acontecia anteriormente, os julgamentos modernistas pós-22, ao que parece, pouco citaram temáticas, personagens e outros aspectos presentes no que foi produzido pelo Príncipe dos Prosadores, focando quase que exclusivamente no estilo de escrita. Sendo assim, é impossível negar que a influência exercida pela forma rebuscada de Coelho Neto foi um dos fatores primordiais para o lugar por ele ocupado nas letras brasileiras.

Campos (1962) identifica como problemático nas obras de Coelho Neto o exagero na imaginação, possível de ser identificado nas descrições de suas obras e, para o autor, "essa opulência prejudica não só a sua obra, como o seu estilo" (Campos, 1962, p. 81). Fora isso, o crítico e literato não deixa de reconhecer que, em suma, o estilo adotado por Coelho Neto é a sua marca e, por conseguinte, uma das contribuições por ele realizadas para a literatura brasileira. O próprio Humberto de Campos (1962), ao abordar especificamente o estilo de Coelho Neto e a relação disso com os modernistas, identifica que o Príncipe dos Prosadores, ao ser usado como referência para identificar transformações entre tendências estilísticas, tem evidenciada e comprovada a sua importância para a literatura brasileira. Nas palavras de Humberto de Campos: 
Research, Society and Development, v. 9, n. 7, e593974552, 2020

(CC BY 4.0) | ISSN 2525-3409 | DOI: http://dx.doi.org/10.33448/rsd-v9i7.4552

É comum encontrar-se, em verdade, nos críticos da geração nova expressões como estas "De Coelho Neto a Graça Aranha..."; "De Coelho Neto a Mário de Andrade"; "os que apostaram, voltando ao sr. Coelho Neto...". O poste de chegada avança ou recua, conforme a posição do espectador. O ponto de partida, fixo, invariável, é, porém, o sr. Coelho Neto. Ele representa uma estética, uma escola de estilística, uma fase da nossa história literária, uma geração de que há numerosos sobreviventes, mas de que é, aos olhos da gente nova, o representante mais intransigente e característico. Não é outra, efetivamente, a sua condição, e tomando-o para alvo dos seus tiros de pólvora seca, para bode expiatório dos pecados reais ou imaginários de toda uma tribo, os modernistas não fazem senão aumentar, pelo martírio, uma glória adquirida pelo talento, pelo estudo e pelo trabalho (Campos, 1962, p. 285-286).

A perspectiva de Campos aponta para um resultado que contraria a finalidade inicial do movimento modernista em relação a Coelho Neto, pois, ao utilizarem-no como símbolo passadista, comprovam que o Príncipe dos Prosadores forneceu, além da forte influência, um estilo de escrita que foi um marco na literatura nacional. Campos (1962) menciona também a necessidade de um distanciamento do objeto (as obras de Coelho Neto) para que seja feita uma análise com mais rigor e, incluindo a si mesmo e citando seus contemporâneos, afirma: "Nós, que vivemos no seu tempo, estamos perto demais do monumento para ter uma ideia precisa da sua altura e dos seus arabescos ornamentais" (Campos, 1962, p. 84).

Isto posto, cabe agora lembrar que houve a tentativa de revitalizar a figura do Príncipe dos Prosadores dentro do cenário literário brasileiro, considerando elementos além do estilo. Lopes (1997) resume bem a finalidade disso, colocando que a importância do processo de reabilitação era "ler o romancista e se desfazer dos preconceitos e das intransigências da crítica anterior” (Lopes, 1997, p. 77). Na discriminação da qual Ibid (1997) fala está incluído, além de outros aspectos, o estilo de escrita coelhonetiano, como já foi possível perceber.

Brito Broca (1958) em seu Coelho Neto, Romancista aborda brevemente o estilo do prosador maranhense, citando possíveis justificativas para o mau julgamento deste aspecto das obras de Coelho Neto. Grosso modo, Ibid (1958) coloca em perspectiva o que José Veríssimo já havia feito, de maneira menos amigável: reconhecer que a negação a tal estilo resulta, em parte, da má formação cultural brasileira, pelo fato de, desde o seu início, não utilizar termos mais complexos nos seus contextos comunicacionais. Para Brito Broca, esse aspecto cultural era encontrado não apenas na população em geral, mas também na maioria dos romancistas brasileiros e, de acordo com o autor, isso "explica a repulsa que o estilo de Coelho Neto, opulento e luxuriante, passou a despertar nas últimas décadas" (Broca, 1858, p. 23). 
Por essa perspectiva, é possível acreditar que o conteúdo presente nas obras de Coelho Neto foi coberto por uma barreira (o estilo) que leitores menos familiarizados com determinados termos e estruturas sintáticas não conseguiram ultrapassar, o que configura uma espécie de defeito estrutural percebido pela crítica, mas não é justificativa para alegar uma total inexistência de reflexões e conteúdos pertinentes nas obras do escritor caxiense. Brito Broca (1958) lembra ainda da recepção positiva das obras de Coelho Neto em terras portuguesas $^{3}$, sugerindo que esse é um indício do preciosismo vocabular que o prosador possuía. Brito Broca critica ainda a polarização de opiniões a respeito das obras do escritor maranhense, afirmando que os objetivos dos críticos se limitavam entre atestar ou negar a qualidade dos livros de Coelho Neto, e não fazer uma análise minuciosa sobre o que as obras teriam de bom ou ruim.

Com isso, é interessante considerar o estudo de Assis e Lopes (2019), que leva em conta o estilo, especificamente a riqueza lexical, de Coelho Neto e analisa-o a partir da obra Miragem comparada a livros de escritores contemporâneos ao prosador maranhense. Os autores identificam o prosador maranhense como possuidor "de uma produção excessiva, que perpassa praticamente todas as correntes estéticas da literatura, do fim do século XIX a meados do século XX [...] (Assis \& Lopes, 2019, p. 260). Como já identificado, o escritor caxiense não pretendia limitar-se a uma única escola literária, e tal escolha pareceu ter mais peso nos juízos críticos do que as próprias obras.

Gonçalves (2016) em O Rio de Janeiro de Coelho Neto: do império à república, lembra que Coelho Neto escreveu livros com características de várias escolas literárias, porém, não filiou-se a nenhuma, mantendo seu estilo de escrita, o que aumentou ainda mais a dificuldade que os historiadores da Literatura Brasileira tiveram em aceitá-lo e avaliar suas obras.

Sendo assim, e retomando a ideia de Humberto de Campos (1962) anteriormente citada sobre a marca estilística de Coelho Neto, o estilo de escrita empregado pelo Príncipe dos Prosadores teve duas consequências: a individualidade que identifica a importância do escritor na história da literatura brasileira, colocando-o como um dos símbolos de uma fase na literatura, e, em contrapartida, a aversão às suas obras por parte de muitos críticos, e consequentemente de outros tipos de leitores, o que, certamente, contribuiu para que, com o passar do tempo, as obras escritas por Coelho Neto fossem cada vez menos lidas.

\footnotetext{
${ }^{3}$ É importante lembrar que José Veríssimo já falava dessa recepção positiva de Coelho Neto em Portugal, mas citava-a de maneira não muito otimista.
} 
Nesse sentido, é perceptível que a recepção inicial, o estilo e outros aspectos dentro da construção da história da Literatura Brasileira, e não apenas as obras por Coelho Neto escritas, foram fortes influenciadores do processo que fez dele um autor pouco lido em terras brasileiras a partir de determinada fase da literatura nacional. Portanto, faz-se necessária uma avaliação de como esse processo influencia as possíveis interpretações das obras coelhonetianas, tendo como base a complexa recepção histórica de Coelho Neto e de suas obras.

\section{Recepção Histórica: Interpretações e Influência}

A recepção de Coelho Neto na literatura brasileira é abordada aqui baseada, em grande medida, nos estudos fornecidas pela Estética da Recepção, teoria que versa sobre a relação autor-obra-leitor, e relacionando tal recepção com as posições ocupadas pelo literato caxiense no cenário literário brasileiro ao longo de sua vida, entendendo-as como aspectos que, em grande medida, participaram ativamente da sucessão de recepções que os livros do escritor maranhense obtiveram por parte do público-leitor e que, somadas, formam a recepção histórica para a qual esta seção dedica-se. Além disso, os aspectos trabalhados anteriormente (recepção inicial e estilo) são, também, importantes agentes determinantes das condições de recepção literária. Soma-se a isso a reflexão sobre o contexto no qual a obra é escrita e lida, pois são fatores extraliterários que possuem validade na relação entre público e obra.

Como já afirmado anteriormente, a recepção inicial de Coelho Neto foi positiva, suas produções eram muito lidas e elogiadas, colocando o prosador maranhense como um literato de prestigio e um escritor bastante promissor. Porém, com o passar dos tempos, as suas obras foram, com uma frequência crescente, alvo de críticas negativas e, por vezes, o próprio autor era atacado. A sucessão de recepções aconteceu ao mesmo tempo em que o público-leitor sofreu transformações ideológicas e sociais. Tal público-leitor teve, além das influências da crítica literária, diferentes critérios de avaliação para atestar ou negar a qualidade de uma obra ou de um escritor. Hans Robert Jauss (1994), importante teórico da Estética da Recepção, identifica a relação entre literatura e leitor em duas implicações igualmente importantes: a estética e a histórica. Segundo ele: 
A implicação estética reside no fato de já a recepção primária de uma obra pelo leitor encerrar uma avaliação de seu valor estético, pela comparação com outras obras já lidas. A implicação histórica manifesta-se na possibilidade de, numa cadeia de recepções, a compreensão dos primeiros leitores ter continuidade e enriquecer-se de geração em geração, decidindo, assim, o próprio significado histórico de uma obra e tornando visível a sua qualidade estética (Jauss, 1994, p. 23).

Pensando na posição de Coelho Neto na literatura brasileira e considerando a perspectiva proposta por Jauss (1994), é possível compreender que nem a recepção inicial e nem as recepções de outras épocas podem ser definidoras incontestáveis da qualidade que as obras coelhonetianas possuem. Isso pode ser verificado com mais legitimidade na sucessão de recepções em diferentes momentos e a influência disso na recepção seguinte, conforme a perspectiva de Jauss (1994). Nesse sentido, é importante considerar mudanças e permanências nos perfis de leitores e de juízos críticos emitidos por diferentes grupos ou pessoas em temporalidades distintas que se ocuparam com a literatura e com a crítica literária. Gonçalves (2016) diz, sobre o prosador caxiense, que "o público que lia, no Brasil do século XX, era formado por pessoas que se identificavam com o estilo do Autor" (Gonçalves, 2016, p. 27). A recepção inicial de Coelho Neto corrobora tal afirmativa.

Em contrapartida, a rejeição modernista demonstra parâmetros e ideias que tinham como base, a priori, interesses diferentes daqueles que possuíam os leitores do passado, e na intenção de romper com uma literatura entendida por eles como passadista e elitista, alguns escritores modernistas não economizavam críticas depreciativas a quem consideravam como o símbolo de um fazer literário que deveria ser combatido: Coelho Neto. Entretanto, o que é apresentado por Jauss (1994) permite lembrar o já citado José Veríssimo (1907) e relacioná-lo com os interesses modernistas a respeito da literatura brasileira. O crítico brasileiro defendeu, de maneira geral, um uso da linguagem e a criação de um conteúdo que contemplassem totalmente os elementos nacionais, defesa essa também feita pelos modernistas de 22 e também em nome da ideia de valorização do povo e da cultura existente no Brasil, livre das amarras lusitanas.

Como já foi verificado, os modernistas não foram os únicos que provocaram o esquecimento de Coelho Neto no meio literário brasileiro, outros já o faziam. Nesse sentido, é possível afirmar que a sequência de recepções e os comentários depreciativos por parte da crítica especializada influenciaram a rejeição de Coelho Neto, tendo nos modernistas o ápice do processo de recepção negativa. As ideias vigentes sobre a forma pela qual a literatura deveria ser produzida resultaram, em certa medida, na mudança de perfil do público-leitor e, 
junto à euforia modernista, contribuíram cada vez mais para que fossem rejeitadas e esquecidas as obras de Coelho Neto.

Tendo em mente tal situação, vale destacar que isso se deve, de certa maneira, às mudanças ocorridas na própria sociedade, o que altera ideias sobre a função da literatura e do seu lugar no meio social. Com isso, é possível perceber que, se a recepção de determinada obra ou autor está ligada às estruturas nas quais a literatura é produzida, as interpretações feitas são influenciadas pelo que é entendido, em determinada época, como a função a ser cumprida por escritores através de suas obras, e não apenas ao caráter puramente estético de uma obra ou a uma dita evolução no fazer literário com o passar do tempo. Dentro dessa perspectiva, Jauss (1994) afirma que

Pode-se tentar apreender também a mudança estrutural na "evolução literária" não de forma substancialista, como "transformação" de formas e conteúdos literários, mas de maneira funcional, como "reocupação" esta que pode ser condicionada e provocada a partir tanto do interior - isto é, da lei imanente de um desenvolvimento do gênero quanto do exterior - ou seja, por estímulos e pressões advindas da situação históricosocial (Jauss, 1994, p. 49).

Nesse sentido, considerar o aspecto histórico-social no qual o público-leitor está situado é importante para que seja entendida, além da possível evolução da literatura, as interpretações feitas sobre um escritor ou sobre uma obra. No caso de Coelho Neto, considerando as críticas negativas e o boom modernista, faz-se perceptível que a ideia levantada por Jauss (1994) é de grande valia para entender alguns motivos pelos quais o prosador caxiense teve sua imagem denegrida e suas obras esquecidas. Ibid (1994, p. 25) afirma ainda que "o contexto histórico no qual uma obra literária aparece não constitui uma sequência factual de acontecimentos forçosamente existentes independentemente de um observador".

Com isso, fica clara a importância que o ato da leitura exerce na renovação dos sentidos que a obra literária pode sugerir. É importante destacar aqui que, assim como a obra e o autor, o público leitor não está em um vazio, mas em um contexto histórico-social que exerce grande influência sobre suas leituras. Lopes (1997), percebendo que Lima Barreto atribui o sucesso de Coelho Neto ao prestígio social que o escritor caxiense possuía, verifica que o público-leitor do primeiro quartel do século XX já dava significativa importância para a biografia dos escritores, lugares por eles frequentados e demais aspectos que identificavam os literatos, e não exclusivamente às qualidades estilísticas e estéticas das obras literárias. 
Ibid (1997), continuando na mesma perspectiva, entende que "a chave de leitura para a compreensão desta literatura passa por essa relação autor-público, cuja mediação paradoxalmente não é a obra literária, mas a imagem socialmente construída do escritor" (Lopes, 1997, p. 30). Diante do exposto, é observável que, em circunstâncias social e ideologicamente estabelecidas, a recepção histórica de Coelho Neto esteve intensamente sujeita às influências extraliterárias que culminaram em uma avaliação das obras a partir do escritor, e não o contrário. Talvez um dos comentários que melhor denote isso é o de Jorge Amado, quando fala sobre a leitura por ele feita de uma das obras de Coelho Neto, A capital federal (1915). Jorge Amado revela:

Os escritores não-modernistas a gente combatia, sem ter lido. Eu sempre conto que tinha vergonha de meter o pau em Coelho Netto, pois lera e gostara de um livro dele, A capital federal, mas a gente tinha que esculhambar Coelho Netto não é mesmo? Esse é um remorso que vou carregar a vida toda, de ter achado o livro ótimo e falando mal do autor, mas Coelho Netto era para nós o símbolo do atraso em matéria de literatura (Amado, 1981, 12, citado por Gonçalves, 2016, p. 24. Grifo da autora).

Resultam disso juízos de valor que, ao serem intensamente fortalecidos, criavam nos leitores pré-conceitos sobre o que esperar dos livros de Coelho Neto. Isso revela que as interpretações feitas por muitos leitores, incluindo críticos e outros literatos, não eram baseadas apenas em critérios subjetivos de qualidade estética, mas também no que já esperavam dos escritos do prosador maranhense por conta dos variados aspectos préestabelecidos pelas instâncias relacionadas à literatura, criando o que Jauss (1994) denomina de horizonte de expectativa.

O horizonte de expectativa, nos estudos de Jauss (1994), se qualifica como o fator que determina as possíveis reações dos leitores no momento em que entram em contato com determinada obra literária, e é criado a partir da relação entre as experiências literárias prévias dos leitores, influências de determinados gêneros, estilos ou formas, além da posição social e histórica do público-leitor. O teórico assevera que a obra literária surge "por intermédio de avisos, sinais visíveis e invisíveis, traços familiares ou indicações implícitas, predispõe seu público para recebê-la de uma maneira bastante definida" (Ibid, 1997, p. 28).

Tais sinais, no caso de Coelho Neto, realmente definiam as interpretações que seriam feitas, contribuindo para que a imagem do escritor fosse fortemente ligada a uma espécie de passadismo desprovido de qualidade literária. É importante lembrar que, durante um período relativamente longo de sua vida, Coelho Neto se viu na obrigação de escrever com bastante 
(CC BY 4.0) | ISSN 2525-3409 | DOI: http://dx.doi.org/10.33448/rsd-v9i7.4552

frequência, o que, como Veríssimo já havia verificado, comprometeu a qualidade de uma parte das obras do prosador maranhense. Sendo assim, é necessário destacar o valor das críticas negativas, desde que baseadas mais em avaliações justas e sinceras do que em ideais pré-estabelecidos, que se tornam mais significativos do que a própria leitura e apreciação dos livros ao serem realizadas as interpretações.

As impressões ruins sobre Coelho Neto tinham valor maior para aqueles que já estavam absorvidos pelos estereótipos criados a respeito dele, fortalecendo ainda mais os argumentos de recepções registradas em obras críticas ou em textos veiculados nos jornais e nas revistas. A esse respeito, é interessante a posição apresentada por Karlheinz Stierle (1979), ao afirmar que

O próprio potencial da recepção, de cuja apreensão o texto ficcional necessita, ainda não é bem captado pela descrição de recepções isoladas. Onde há recepções registradas de obras particulares, trata-se sempre de recepções já articuladas, cuja particularidade nunca retrata simplesmente a complexidade da experiência concreta da recepção, mas que a estiliza de acordo com conceitos (Konzepte) e normas em vigor e com interesses particulares (Stierle, 1979, p. 137).

No caso de Coelho Neto, as normas em vigor e os interesses por trás dos juízos críticos emitidos contribuíram de maneira excessiva para que a recepção dele e de suas obras fosse, além de complexa, muito negativa, o que renegou o literato caxiense ao esquecimento. Mas, como já mencionado, a cadeia de recepções influencia as recepções posteriores e, talvez por conta disso, são realizadas, através de algumas pesquisas e análises em literatura, revisões sobre a obra, no sentido de conjunto de livros, deixada por Coelho Neto. Uma ideia ao tornarse lugar-comum sobre determinada obra, "um esforço particular faz-se necessário para que se possa lê-la 'a contrapelo' da experiência que se faz hábito e, assim, divisar-lhe novamente o caráter artístico" (Jauss, 1994, p. 32).

Sendo assim, tendo em vista que a obra de Coelho Neto, ao ser recepcionada historicamente, foi influenciada por inúmeros fatores que impediram interpretações consistentes, baseadas em qualidade das obras, esclarece, além das influências, a necessidade de uma revisão das obras do autor. Portanto, a análise realizada a partir desse prisma colabora com a reavaliação de Coelho Neto tendo em mente os fatores que contribuem e os que nada acrescentam a uma avaliação justa, que considere os aspectos positivos e negativos de um dos escritores mais fecundos na literatura brasileira. 


\section{Considerações Finais}

Com o objetivo de trazer à tona algumas questões para a compreensão dos motivos por detrás do quase completo esquecimento de Coelho Neto na historiografia literária brasileira, o artigo traçou um panorama histórico da contribuição do Príncipe dos Prosadores para as letras brasileiras e, alicerçado pelas concepções da Estética da Recepção, demonstrou que não apenas a campanha modernista, principalmente na figura de Lima Barreto, mas a predileção por uma sintaxe e léxico mais lusitanos, sem deixar de mencionar o próprio mercado editorial, foram importantes agentes que deixaram Coelho Neto à sombra dos holofotes literários.

Além de estudantes e pesquisadores da área de Literatura, o texto pode trazer interessantes reflexões para estudiosos da nossa historiografia literária e de como relações extraliterárias, sempre com fundos ideológicos, não se pode esquecer, atuam na transformação e reconfiguração lenta e constante das nossas Letras.

Diante do que foi apresentado, torna-se inegável que são necessários esforços e trabalhos intelectuais a respeito do legado deixado pelo escritor maranhense, para que os fatores extraliterários passados não impeçam leitores e pesquisadores contemporâneos de explorarem um material extenso da literatura brasileira que, durante muito tempo, foi colocado à margem dos estudos em literatura.

Após a onda modernista, como já foi dito, tiveram início as tentativas de reavaliação das obras sem a influência demasiada dos fatores extraliterários. Mas, tendo em vista que as obras de Coelho Neto permanecem esquecidas por grande parte dos leitores, faz-se necessária a continuidade dos estudos e das pesquisas sobre ele e suas obras por diferentes perspectivas, reconhecendo o real valor do Príncipe dos Prosadores para a literatura brasileira.

\section{Referências}

Assis, E.C.P. de., \& Sousa, A.S. (2017). "Efeito de real” versus sobrenatural: um conflito necessário à construção da fantasticidade em Esfinge, de Coelho Neto. Revista de Letras Juçara, Caxias, 1(1): 144-161, jul. Disponível em: https://ppg.revistas.uema.br/ index.php/jucara/article/view/1324/1070. Acesso em: 02 abr. 2020.

Assis, E.C.P. de., \& Lopes, D. (2019). A estatística textual computadorizada e a literatura brasileira: uma análise do romance Miragem, de Coelho Neto. Studia Iberystycnze, Cracóvia, 18(1): 259-270, (dez). https://doi.org/10.12797/SI.18.2019.18.18. 
Assis, M. de. A semana (1892 - 1890). Disponível em: https://www.machadodeassis.ufsc.br /obras/cronicas/CRONICA,\%20A\%20semana,\%201892.htm\#C1895. Acesso em: 22.01.2020.

Bezerra, C. E. de. (2009). Adolfo Caminha: um polígrafo na literatura brasileira do Século XIX (1885 - 1897). $1^{\circ}$ Edição. São Paulo: Cultura Acadêmica.

Broca, B. (1958). Coelho Neto, romancista. In: NETO, Coelho. Obra seleta. Vol. 1: José Aguilar Ltda.

Caminha, A. (1895). Cartas literárias. $1^{\circ}$ Ed. Rio de Janeiro: Tipografia Aldina.

Campos H. de. (1962). Crítica: primeira série. 1.ed.. São Paulo: Mérito S.A, 1962.

Gonçalves, M. R. (2016). O Rio de Janeiro de Coelho Neto - do império à república. Tese de doutorado, Universidade Federal do Rio Grande do Sul, Porto Alegre, RS, Brasil.

Jauss, H.R. (1994). A história da literatura como provocação à teoria literária. $1^{\circ}$ Ed. São Paulo: Ática S.A.

Lopes, M. A. (1997). No purgatório da crítica: Coelho Neto e o seu lugar na história da literatura brasileira. Dissertação de Mestrado, Universidade Estadual de Campinas, Campinas, SP, Brasil.

Pereira, AS. et al. (2018). Metodologia da pesquisa científica. [e-book]. Santa Maria. Ed. UAB/NTE/UFSM. Acesso em: 16 maio 2020. Disponível em: https://repositorio.ufsm.br/ bitstream/handle/1/15824/Lic_Computacao_Metodologia-Pesquisa-Cientifica.pdf?sequenc $\mathrm{e}=1$.

Rosso, M. (2010). Lima Barreto versus Coelho Neto: um fla-flu literário. $1^{\circ}$ Edição. Rio de Janeiro: Difel. 
Sousa, A.P.N. de., Correia, M.V.S., \& Assis, E.C.P. de. (2018). A digitalização da literatura maranhense: o portal Maranhão. Letra Magna, São Paulo, 23, (2): 803-815, dez. Disponível em: http://www.letramagna.com/artigos_23/artigo_lit_03_23.pdf. Acesso em: 15 abr. 2020.

Stierle, K. (1979). Que significa a recepção de textos ficcionais? In: L. C. Lima. A Literatura e o Leitor: Textos de Estética da Recepção. (pp. 119-171) $2^{\circ}$ Ed. Rio de Janeiro: Paz e Terra.

Veríssimo, J. (1901). Estudos de literatura brasileira: $1^{\circ}$ Serie. $1^{\circ}$ Ed. Rio de Janeiro: Garnier Livreiro-Editor.

Veríssimo, J. (1904). Estudos de literatura brasileira: $4^{\circ}$ Serie. $1^{\circ}$ Ed. Rio de Janeiro: Garnier Livreiro-Editor.

Veríssimo, J. (1907). Estudos de literatura brasileira: $6^{\circ}$ Serie. $1^{\circ}$ Ed. Rio de Janeiro: Garnier Livreiro-Editor.

\title{
Porcentagem de contribuição de cada autor no manuscrito
}

\author{
Marcus Vinicius Sousa Correia - 60\% \\ Emanoel Cesar Pires de Assis - 40\%
}

